\title{
Improving Reading Fluency through Videoscribe for Student with Learning Disability
}

\author{
Zulmiyetri ${ }^{* *}$, Kasiyati ${ }^{1}$, Grahita Kusumastuti ${ }^{1}$ \\ ${ }^{1}$ Universitas Negeri Padang \\ *Corresponding author, e-mail: yetrizulmiyetri@gmail.com
}

\begin{abstract}
This study aims to determine the effect of videoscribe for improving reading fluently ability for student with learning disability. This research uses single subject research (SSR) experiment, A-B-A design and data analysis technique using visual graph analysis. The subject of this research is student with learning disability. Target behavior in this study is the speed of reading fluently in short discourse text. Observations were conducted in three sessions. First is baseline session (A1), second, interventions through media videoscribe (B) and last session baseline (A2). Based on the results of research, we knew that the ability of children in reading fluently can be increased through videoscribe. At the baseline condition (A1), the reading fluently ability of the student increases from the duration of four point five minutes to four minutes. In intervention condition (B), the duration becomes shorter in one minute. At the baseline condition (A2) the duration becomes shorter, even without any intervention. Based on data analysis, it can be explained that direction tendency, stability tendency, data trending trend, and level change increase positively, and overlape percentage on inter-condition analysis is $0 \%$. It can be concluded that the media videoscribe can improve reading fluently ability for student with learning disability.
\end{abstract}

Keywords: reading fluently, learning disability, Videoscribe

How to Cite: Zulmiyetri, Z., Kasiyati, K., Kusumastuti, G. (2019). Improving Reading Fluency through Videoscribe for Student with Learning Disability Title manuscript. International Journal of Research in Counseling and Education, 3 (2). pp. 76-81, DOI: 10.24036/0056za0002

This is an open access article distributed under the Creative Commons 4.0 Attribution License, which permits unrestricted use, distribution, and reproduction in any medium, provided the original work is properly cited. @2019 by author and Universitas Negeri Padang.

\section{Introduction}

Reading is one of important thing in human life, without reading people will not able to communicate with each other. Because reading is the window of knowledge in the learning process. If children in school age has low level in reading ability, then they will have problem in learning various subjectsin the the next class. One of the reading skills that should be enhanced and trained is the ability to read smoothly, which is an important component in reading skills. Research by Pikulski \& Chard (2005) stated that fluency as a bridge from word recognition accuracy to text comprehension. Students who can not read fluently will have difficulty in understanding the contents of reading text.

Reading fluently should have been learned in grade II and grade III, but there are students who are not able to read fluently. This is in line with the opinion of Chard, Vaughn, \& Tyler (2002) which stated that student with learning or reading disabilities demosntrate difficulties in the area of fluency. Students with learning disabilities have a problem in basic psychological involved in understanding and using the language verbally or on writing. Abdurrahman (2003) explained that learning disabilities can manifest as a deficiency in one or more academic areas, included subjects that are specific such as reading fluency.

Abdurrahman ( 2003) said that students with learning disabilities is a learning difficulty that associated with development learning disabilities, included: a motor disorder, perception, language, communication and learning difficulties in the adjustment of social behavior, and the difficulty of academic learning which include : reading, writing and mathematics. This finding was similar to that of Tindal, Nese, Stevens, \& Alonzo (2016), who found that performance on measures of oral reading fluency correlated significantly with special education status The types of reading that need to be mastered by students according to Abbas (2006) is reading fluently, intensive reading, reading languages, and reading quickly. The large number of students with disabilities who experience reading difficulties, as well as students who may not be eligible for special 
education services, but who also struggle, requires the creation of comprehensive reading instruction that includes a focus on reading fluency and comprehension (Speece \& Ritchey, 2005)

The problem that allowed by students with learning disabilities in reading, especially reading fluency is the introduction of a difficult word, beyond the word, less in use expression, read word by word, the reading speed is low, not use intonation and not pay attention to punctuation. Good readers read with sufficient rate to process words effortlessly and think about what they read (Paris, 2005).Based on the findings of the study, students have learning problems because of their ability to read fluently is low. The students is still fail in reading short text, less accurate reading word by word, and not pay attention to punctuation. When students read slowly, they tend also to read less text (Allington, 2001; Jenkins, Fuchs, van den Broek, Espin, \& Deno, 2003)

Because of the problems confronted by students with learning disabilities in reading fluency, the researcher pursue to improve the reading fluency ability using videoscribe. Videoscribe is a learning video animation composed of a series of text, sounds and images. Audain (2014) suggested that a blank canvas where your drag image and write words to explain a concept . It understood that videoscribe is a blank canvas that can be inserted the picture and write words to explain a story or concept. Aligned with the opinion of Air, Oakland, \& Walters (2014) videoscribe is whiteboard animation. Whiteboard animation show images drawn onto a white background, they unfold in sync with voicecover to communicate your ideas in a clear, linear narrative. Applying the videoscribe will facilitate students in participating in read fluency learning, because either way to improve the ability of read fluently is by demonstrate how to read fluently. Based on the describe above, videoscribe can help students to improve the reading fluency ability.

\section{Method}

This research used single subject research. This research analyze whether there is a causal relationship that is imposed on the subject. This study used A-B-A research design. A1 is baseline phase before intervention. B is treatment phase, and A2 is second baseline after intervention. Dependent variable in this study is ability to read fluency. Reading fluency is how long the students able to read fluently and properly, then the duration was measured using a stopwatch. In this study, researcher concern to the students with learning disabilities able to read a discourse quickly and accurately. While the independent variable in this study is the videoscribe. Videoscribe is a learning video animation composed of a series of text, sounds and images. Videoscribe is new model for telling. Researcher will measure how long reading duration that used by the students.

Research subject in this study is students with learning disabilities, particulary students with reading fluency problem. The students is underdeveloped in reading a discourse, not use intonation while reading, not pay attention to punctuation, takes a long time in reading, and reading speed is low. So that to finish the reading, the students with learning disabilities need longer duration thannk their friends who have no reading fluency problems. Data collected by observation how long time that needed by dtudents for reading text. The instrument in this study used duration instrument. Researchers directly measured the baseline A1 of the student in reading fluency.

Videoscribe has been customized with illustrations of the story. Vidoescribe starts with displaying text of the story then, accompanied by voice and the corresponding image showed. Student is asked to pay attention to the impressions and the student imitate the reading gradually. If the student is able to read the text fluently and precisely then it will be processed on the next text. If the student is incorrect in reading the text of the story, the vidoescribe will be repeated. Then the researchers accomplish the reading assessment through reading text without videoscribe. So that the duration that taken by the students in completing the reading being shorter.

Data directly collected through reading test of the discourse. Researchers measured the ability to reading fluently of student with the criteria of the target duration behavior which is useful to know how long duration that needed by student in reading fluently. After that, the data was analyzed using visual graphics analysis technique by plotting the data into the chart.

\section{Results and Discussion}

\section{Result}

This research was conducted in 22 meetings where baseline (A_1) performed in 6 meetings, the intervention phases (B) performed in 11 meeting and baseline after the intervention (A_2) performed in 5 
times. Every meeting, the condition is measured by calculating the duration that needed by students for reading fluently a short text.

Data result in baseline A1, duration that needed by students to read fluently, are 4.5 minutes, 4.5 minutes, 4.5 minutes, 4 minutes, 4 minutes and 4 minutes. Data result in intervention (B), duration that needed by students to read fluently, are 2.5 minutes, 2.5 minutes, 2 minutes, 1.5 minutes, 1.5 minutes, 3 minutes , 1.5 minutes , 1.5 minutes, 1 minutes, 1 minutes and 1 minutes. Data result in baseline A2, duration that needed by students to read fluently, are 2.5 minutes, 2 minutes, 2 minutes, 2 minutes, 2 minutes and 2 minutes.

From the data results of each session can be identify comparison the three parts of this study, as follows :

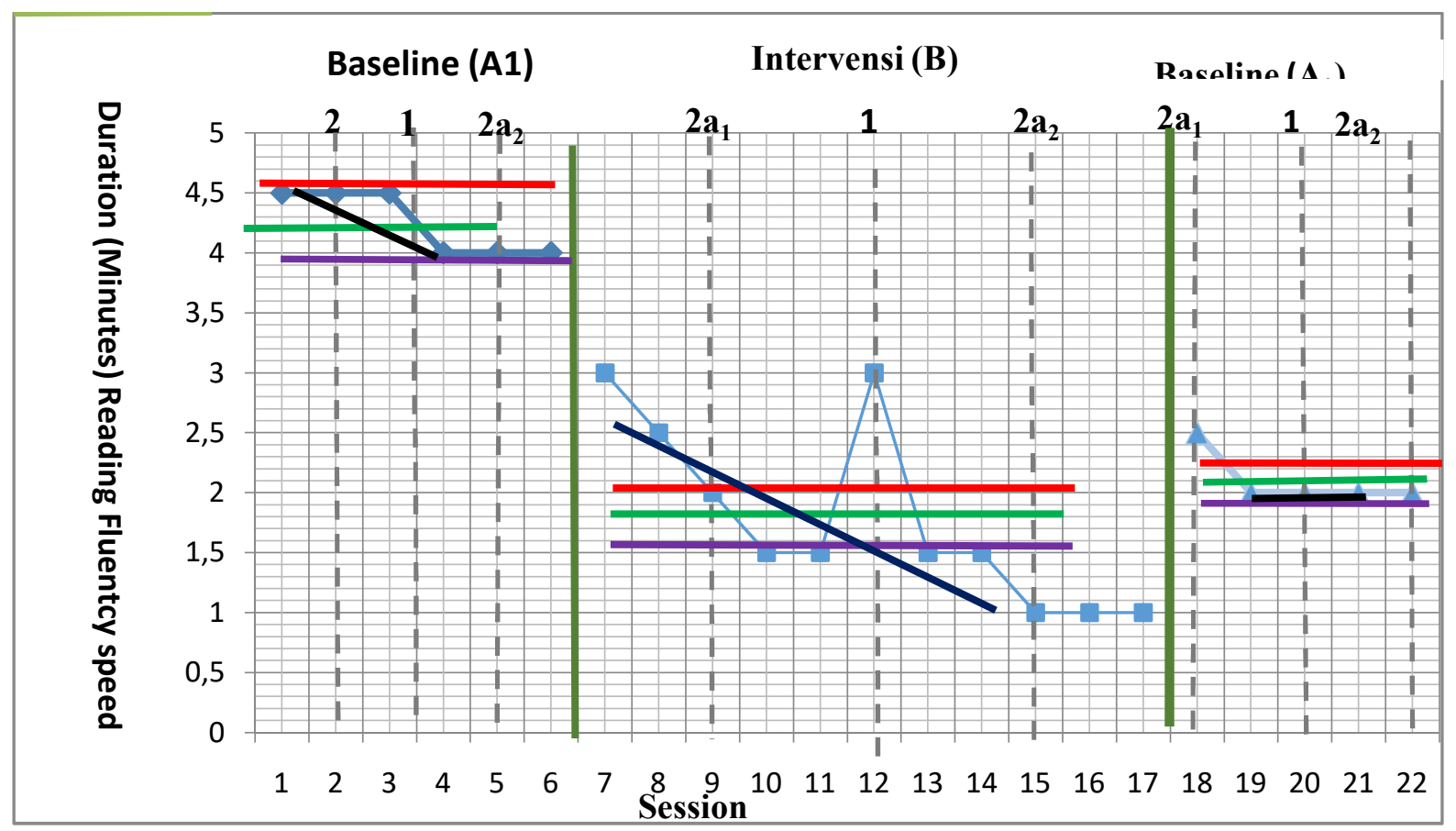

Figure 1. In the conditions analysis chart of the reading fluency ability.

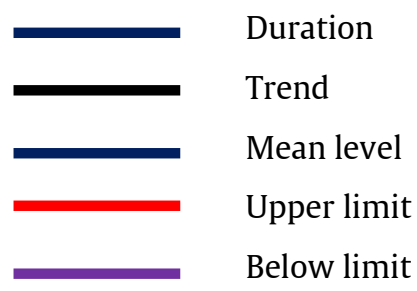

Summary result of in condition data analysis about reading fluency in every phase could be identify in Table 1.

Tabel 1. In condition data analysis about reading fluency

\begin{tabular}{lccc}
\hline Target & Baseline $\left(\mathrm{A}_{1}\right.$ & Intervensi $(\mathrm{B})$ & Baseline $\left(\mathrm{A}_{2}\right)$ \\
& & & \\
\hline Result & $4.5,4.5,4.5$ & $3,2.5,2,1.5,1.5,3,1.5,1.5$, & $2.5,2,2,2,2$ \\
& $4,4,4$ & $1,1,1$ & \\
\hline Mean & 4,25 & 1,77 & 2,1 \\
\hline Trend & $(+)$ & $(+)$ & $(+)$ \\
\hline Range of Stability & 0,68 & 0,45 & 0,38 \\
\hline
\end{tabular}




\begin{tabular}{llll}
\hline Mean level & 4,25 & 1,77 & 2,01 \\
\hline Upper limit & 4,59 & 1,995 & 2,29 \\
\hline Below limit & 3,91 & 1,545 & 1,91 \\
\hline Percentage of Stability & $100 \%$ & $0 \%$ & $80 \%$ \\
\hline
\end{tabular}

Based on the table can be identify that the conditions of the baseline (A_1) stopped at the sixth meeting. Data showed that the duration of speed reading fluency reduced from the first day until the sixth day. The first observation the student is able to read fluently in 4.5 minutes. While in the second observation, the duration of reading speed is fixed at 4.5 minutes. Speed reading fluency duration of student in fourth observation until the sixth fell as much as $1 / 2$ minute and being 4 minutes. This occured because the discourse that read by student is same from the first day until the sixth day. Thus, researchers continue to the intervention.

The length of the condition on intervention (B) was 11 minutes, of 2.5 minutes, 2.5 minutes , 1.5 minutes, 1.5 minutes, 1.5 minutes, 2.5 minutes, 1.5 minutes, 1.5 minutes, 1 minute, 1 minute, and 1 minute. After treatment, the estimated trend direction on the condition of reading fluently decreased. Conditions when student has been given the intervention has stabilized, then, researchers continue to the conditions baseline (A2). The length of the condition on second baseline (A2) was 5 minutes, of 2.5 minutes, 2 minutes , 2 minutes, 2 minutes, and 2 minute. It seen that direction tendency of the student decreased, meaning that the reading ability of the student increased.

Tabel 2. Data analysis about reading fluency

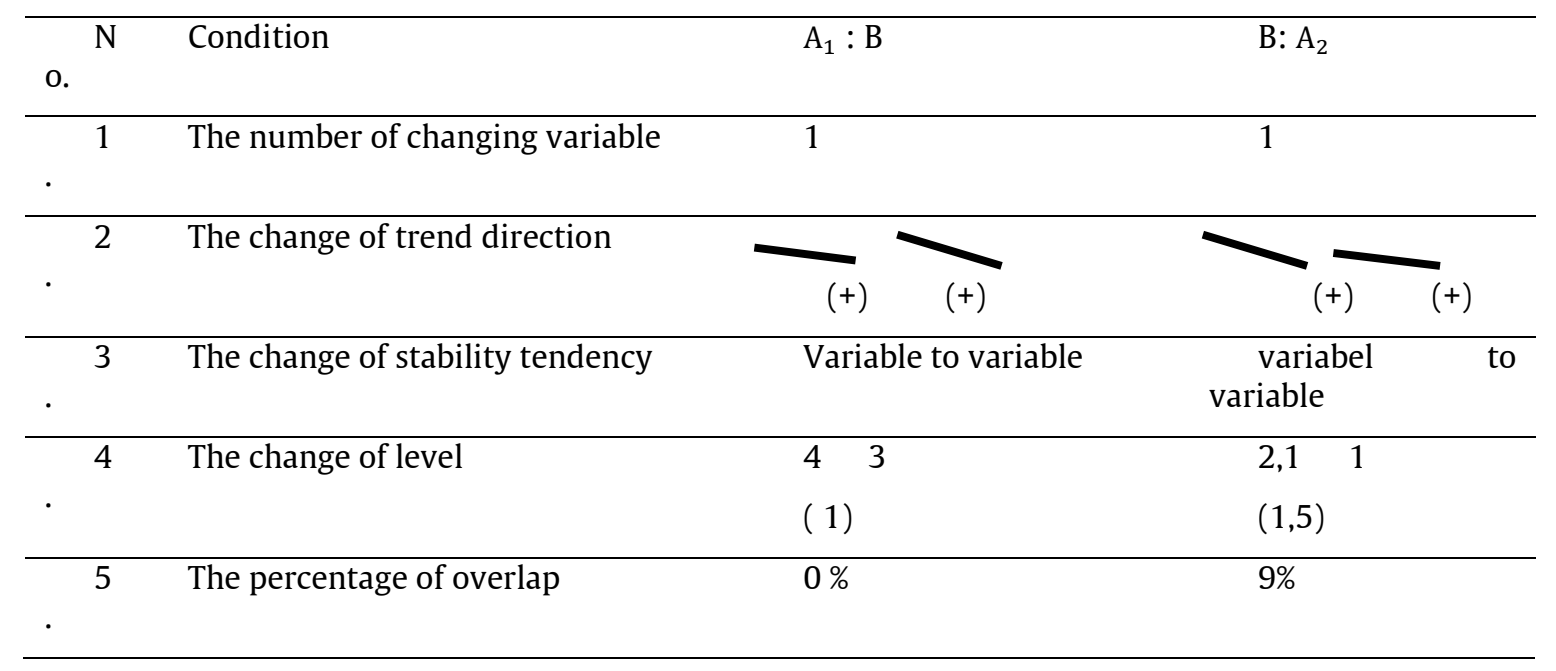

The results of hypothesis showed that before being given treatment (A1), a tendency towards speed reading fluency improved but not significantly. when treatment was given at intervention (B) the direction tendency of reading fluency speed increased $(+)$. This proved that the videoscribe can enhance the ability of reading fluency for student with learning disabilities. The smaller percentage of overlape is better for intervention effect to change the target behavior. Data overlape of the baseline (A1) and the baseline (A2) is $0 \%$. Thus it can be interpreted that the ability of the students with learning disabilities increased after given the intervention. Based on the data analysis can be described that the student with learning disabilities.

\section{Discussion}

Based on the problems, the ability to read fluency is low. The student look stuck in reading a short text, the reading speed is low, the student read word by word and often stopped in the word in the discourse. Whereas the student had been sitting in grade IV and the required lesson is intensive reading or reading comprehension.

According to Abbas (2006) reading fluency is a clearly voiced reading, not doubt, the sound volume is steady and the speed was fixed. Aligned to Rasinski, Rupley, Paige, \& Nichols, (2016) which stated that read with adequate speed and word recognition automaticity, they also read aloud with good prosody or expression, using appropriate phrasing, intonation. When the student has difficulty in reading fluently, then 
the student will be difficult to understand the text reading. The purpose of reading fluently is the student easily understand the content of the reading, quickly and exactly.

In order to increasing the reading fluency of student with learning disabilities, needed various media that appropriate with student needs so that students more motivated and focused in following the learning. Through videoscribe that are able to present the illustration of the story clearly and simple, so that the child easily focused in following the learning process. Videoscribe can create multisensory experience, which can help students understanding, a good memory, and provoke curiosity so that learning becomes fun. According to Air, Oakland, \& Walters (2015) said that videoscribe improve learning, getting and holding attention, putting people in good mood. Based on the describe, videoscribe is able to use in learning proses. Because videoscribe can make learning become fun, students is able to understand the lesson that taught and student more motivated to join the instructional. Another results also showed that teachers can increase the amount of practice to promote reading fluency by incorporating computerassisted instruction into daily reading sessions (Dukes \& Ming, 2008).

Instructional using videoscribe should concern on script that easy to understood. The thing that should concern in making script according to Air et al., (2015) is what kind impression are you trying to give?, who is your audiens and what is your video about?. In this research, which will be given effect is the reading fluency for students with learning disabilities. Vidoescribe is adjusted to the needs of the students. Vidoescribe will show short stories that are equipped with sound, image and text, so that the students can following learning to read fluency. The results of in the conditions data analysis and the results of the analysis between the conditions that conducted in 22 conditions which consists of six baseline conditions, eleven intervention conditions, and five baseline after treatment. Before treatment (A1), the tedency direction of the speed reading fluency increased but not significantly, when the treatment is given at intervention (B), the tendency towards the reading speed continues to increase. This proved that videoscribe can enhance the ability of reading fluency for students with learning disabilities. Therefore, a multiple component approach to reading fluency (incorporating several practices into daily reading instruction) that addresses these deficits would most benefit them (Chard et al., 2002)

\section{Conclusion}

Based on the data analysis in conditions and between conditions it can be concluded that the videoscribe could enhance the reading fluency ability of students with learning disabilities. Observation had been conducted in 22 times, 6 times for baseline A1, 11 time in intervention (B) and 5 time in basline A2. This study found that reading fluency increasing after student given treatment by videoscribe. Based on data analysis either in condition or between conditions showed an increase in the ability to read fluently for the students with learning disabilities. So that the students can read fluently and correctly. The results of this study showed that the videoscribe is effective for improving reading fluency skills of students with learning disabilities.

\section{References}

Abbas, S. (2006). Pembelajaran Bahasa Indonesia Yang efektif di Sekolah Dasar: Jakarta: Depdiknas.

Abdurrahman, M. (2003). Pendidian Anak Kesulitan Belajar. Jakarta: Rineka Cipta.

Air, J., Oakland, E., \& Walters, C. (2014). The Secrets Behind The rise Of Video Scribing. Bristol: Sparkol Books.

Air, J., Oakland, E., \& Walters, C. (2015). How to design Your Own Whiteboard Animation. Bristol: Sparkol Books.

Allington, R. (2001). What really matters for struggling readers? Designing research-based programs. New York: Longman.

Audain, J. (2014). The Ultimate Guide to using ICT Across The Curriculum. London: Bloomsburry Education.

Chard, D., Vaughn, S., \& Tyler, B.-J. (2002). A synthesis of research on effective interventions for building reading fluency with elementary students with learning disabilities. Journal of Learning Disabilities, $35(5), 386-406$.

Dukes, C., \& Ming, K. (2008). Fluency : A Necessary Ingredient in Comprehensive Reading Instruction in Inclusive Classrooms Fluency : A Necessary Ingredient in Comprehensive Reading Instruction in Inclusive Classrooms. TEACHING Exceptional Children Plus, 4(4), 2-14. 
Jenkins, J. R., Fuchs, L. S., van den Broek, P., Espin, C., \& Deno, S. (2003). Sources of individual differences in reading comprehension and reading fluency. JOurnal of Educational Psychology, 95, 719-729.

Paris, S. . (2005). Reinterpreting the development of reading skills. Reading Research Quarterly, 40, 184-202.

Pikulski, J. ., \& Chard, D. . (2005). Fluency : Bridge Between decoding and reading comprehension. The Reading Teacher, 58, 510.

Rasinski, V. T., Rupley, W. ., Paige, D., \& Nichols, D. . (2016). Alternative Text Types to Improve Reading Fluency for Competent to Struggling Readers. International Journal of Instruction, 9, 164.

Speece, D., \& Ritchey, K. (2005). A longitudinal study of the development of oral reading fluency in young children at risk for reading failure. Journal of Learning Disabilities, 38(5), 387-399.

Tindal, G., Nese, J. F. T., Stevens, J. J., \& Alonzo, J. (2016). Growth on oral reading fluency measures as a function of special education and measurement sufficiency. Remedial and Special Education, 37, 28-40. https://doi.org/10.1177/0741932515590234 